\title{
Prostate Cancer in South Africa: Pathology Based National Cancer Registry Data (1986-2006) and Mortality Rates (1997-2009)
}

\author{
Chantal Babb, ${ }^{1}$ Margaret Urban, ${ }^{2}$ Danuta Kielkowski, ${ }^{1}$ and Patricia Kellett ${ }^{1}$ \\ ${ }^{1}$ NHLS/MRC Cancer Epidemiology Research Group (CERG), National Cancer Registry (NCR), \\ National Health Laboratory Services (NHLS), Johannesburg 2000, South Africa \\ ${ }^{2}$ Faculty of Health Sciences, University of the Witwatersrand, Johannesburg 2000, South Africa \\ Correspondence should be addressed to Chantal Babb; chantal.babb@nhls.ac.za
}

Received 28 February 2014; Accepted 23 April 2014; Published 15 May 2014

Academic Editor: Judd Moul

Copyright (C) 2014 Chantal Babb et al. This is an open access article distributed under the Creative Commons Attribution License, which permits unrestricted use, distribution, and reproduction in any medium, provided the original work is properly cited.

\begin{abstract}
Prostate cancer is one of the most common male cancers globally; however little is known about prostate cancer in Africa. Incidence data for prostate cancer in South Africa (SA) from the pathology based National Cancer Registry (1986-2006) and data on mortality (1997-2009) from Statistics SA were analysed. World standard population denominators were used to calculate age specific incidence and mortality rates (ASIR and ASMR) using the direct method. Prostate cancer was the most common male cancer in all SA population groups (excluding basal cell carcinoma). There are large disparities in the ASIR between black, white, coloured, and Asian/Indian populations: 19, 65, 46, and 19 per 100 000, respectively, and ASMR was 11, 7, 52, and 6 per 100000 , respectively. Prostate cancer was the second leading cause of cancer death, accounting for around $13 \%$ of male deaths from a cancer. The average age at diagnosis was 68 years and 74 years at death. For SA the ASIR increased from 16.8 in 1986 to 30.8 in 2006, while the ASMR increased from 12.3 in 1997 to 16.7 in 2009. There has been a steady increase of incidence and mortality from prostate cancer in SA.
\end{abstract}

\section{Introduction}

Prostate cancer (ICD-O3 code C61.9 and ICD-10 code C61) $(\mathrm{CaP})$ is one of the most common cancers worldwide. The worldwide incidence of $\mathrm{CaP}$ varies greatly between different geographical regions and/or ethnic groups, with men of African descent living out of Africa having some of the highest incidence rates (African American men 234.6 per 100 000) [1, 2]. Compared to Caucasian Americans, African Americans are disproportionately and more frequently diagnosed with $\mathrm{CaP}$ at an earlier age of onset, have higher tumour volume, more advanced (aggressive) tumour stage, higher Gleason score, and higher prostate specific antigen (PSA) levels $[3,4]$. Indeed, there are differences in CaP mortality across men of different population groups; the mortality rate among African Americans (62.3 per 100 000) is 2.4 times the rate of Caucasian Americans (25.6 per 100 000) [1]. By contrast the incidence of $\mathrm{CaP}$ is low in several Asian countries
[5]. The reasons for these differences are still unclear but may be related to differences in testing, referral patterns, access to care, differences in biology of the disease, inherited susceptibility, treatment options, reporting, and diagnosis; these could all influence disparities between different racial, ethnic, and geographic backgrounds $[2,6,7]$.

Data from Africa on $\mathrm{CaP}$ is relatively sparse $[2,8]$. The International Agency for Research on Cancer GLOBOCAN estimated $28000 \mathrm{CaP}$ deaths occurring in Africa in 2008 and predicted this number to double to 57000 by 2030 . There is belief of an underestimation of $\mathrm{CaP}$ in Africa as there may be a high degree of under diagnosis due to poor access to testing and diagnostic facilities [7, 9]. Globally, the incidence of $\mathrm{CaP}$ is increasing due to longer life spans, fewer deaths due to communicable diseases, increased PSA testing in the absence of symptoms, and as yet unknown aspects of westernization of lifestyle [10]. A better understanding of $\mathrm{CaP}$ rates in sub-Saharan Africa might provide valuable 
insight into the aetiology of $\mathrm{CaP}$. The aim of this publication is to summarize data on CaP in South African (SA) men. Knowledge of cancer incidence is vital to inform health policy and effective service provision.

\section{Methods}

The primary source for the data was from the SA pathology based National Cancer Registry (NCR) reports from 1986 to 2006, from which the information on $\mathrm{CaP}$ was summarised by population group $[11,12]$. The population groups are black, white, coloured (mixed ancestry), and Asian/Indian and reflect those used by the census data collected by the SA Government $[13,14]$. The 2011 census indicated that $79.2 \%$ of the SA population were black, $8.9 \%$ white, $8.9 \%$ coloured, and $2.5 \%$ Asian/Indian. More detail was sourced directly from the NCR database and included a breakdown of the CaP subtypes seen through the years of 1999-2006 and the reported ages at diagnosis, allowing for calculation of mean ages of $\mathrm{CaP}$ cases reported to the NCR by population group. No information on stage or grade was available.

The NCR has been operating as a pathology based Cancer Registry with laboratory (microscopically, haematology, histology, and cytology) verified cases being reported and captured since 1986, with 2006 data being the latest year released [11, 12]. The NCR receives pathology reports from all pathology laboratories throughout the country with 84 countrywide laboratories reporting 80000 confirmed cancer cases in 2010 [15]. New SA legislation (National Health Act-Regulations relating to cancer registration, 2011 Act No. 61 of 2006 No. R. 380) is now shifting the registry to a population based surveillance system [16].

Data submitted is coded according to the International Classification for Oncology, third edition (ICD-O3), by trained staff $[15,17,18]$. It is now common practice for the NCR to receive full pathology reports, including clinical details, which makes for more accurate cancer coding and database completeness. When possible, past NCR data are constantly updated with newly developed and improved quality control measures, such as the conversion of data from other coding formats to ICD-O, as well as checking for incorrect/improbable coding [18]. Reporting is done in ICD-10 coding to allow for comparison with global registry reports.

The use of age standardised rates (ASR) is necessary when comparing several populations that have different age compositions. Age standardisation for NCR by population group was done using mid-year estimates for the SA population from Dorrington et al. [19] to provide crude estimates and the 1960 world standard population [20] to per 100000 .

In addition, data from Statistics SA on mortality by malignancy for the SA population (1997-2009) was made available [21, 22]. From this data age standardised mortality rates were calculated using the direct method with the same mid-year populations used for the NCR [19, 20]. Statistics SA reports mortality on a national level [21] and not by population group but, on request from NCR, reporting of
TABLE 1: The number of prostate cancer cases reported to the South African pathology based National Cancer Registry, years 1986-2006, by population group.

\begin{tabular}{lccccc}
\hline & All & Black & White & Coloured & Asian \\
\hline 1986 & 1401 & 559 & 689 & 126 & 27 \\
1987 & 1522 & 627 & 782 & 86 & 27 \\
1988 & 1800 & 698 & 863 & 163 & 13 \\
1989 & 2046 & 762 & 1028 & 166 & 27 \\
$1990-1991$ & 2434 & 941 & 1213 & 183 & 62 \\
1992 & 2424 & 816 & 1108 & 174 & 43 \\
1993 & 2736 & 873 & 1241 & 124 & 33 \\
1994 & 2622 & 532 & 1353 & 75 & 34 \\
1995 & 2504 & 532 & 1226 & 60 & 28 \\
$1996^{*}$ & 2802 & 1074 & $1468^{\wedge}$ & $209^{\wedge}$ & 52 \\
$1997^{*}$ & 3715 & 1265 & $2115^{\wedge}$ & $241^{\wedge}$ & 93 \\
$1998^{*}$ & 4171 & 1432 & 2277 & 396 & 64 \\
$1999^{*}$ & 3860 & 1220 & 2169 & 410 & 59 \\
$2000^{*}$ & 3958 & 1339 & 2051 & 497 & 72 \\
$2001^{*}$ & 4118 & 1325 & 2173 & 537 & 83 \\
$2002^{*}$ & 4318 & 1432 & 2263 & 541 & 83 \\
$2003^{*}$ & 4178 & 1310 & 2271 & 525 & 79 \\
$2004^{*}$ & 4301 & 1367 & 2255 & 588 & 94 \\
$2005^{*}$ & 4346 & 1480 & 2244 & 530 & 92 \\
$2006^{*}$ & 4631 & 1707 & 2253 & 577 & 93 \\
\hline
\end{tabular}

Years 1986-1995 reported observed numbers and years * $1996-2006$ reported adjusted numbers. ${ }^{\wedge}$ In 1996 and 1997 whites and coloureds were reported together; NCR provided the individual figures that are not in the printed report.

cancer mortality by population group was made available for the year 2009 only.

\section{Results}

3.1. Incidence. In 1995, 2504 new cases of CaP were reported and 10 years later, in 2006, there were 4631 new cases (Table 1). Over the 20-year time period, 1986 to 2006, $63886 \mathrm{CaP}$ were reported to NCR. Each year the white population group had the highest number of cases reported. Both the coloured and Asian/Indian population groups have relatively small numbers, with less than a hundred cases reported each year for the Asian/Indian population. Both the black and white population groups have fairly consistent numbers being reported through the years, in particular for the last 5 years of reporting. There is a trend for a steady increase in the number of $\mathrm{CaP}$ cases reported in each population group through the years. The calculated year-on-year percentage change (data not shown) in CaP cases showed that in the period 1986 to 1995 there was quite a large variation in the different population groups (from $+129.6 \%$ to minus $39.5 \%$ ) although for all groups combined it ranged from $+19 \%$ to minus $4.5 \%$. The most dramatic increase occurred between 1996 and 1999 (Figure 1). In the period 1996-97 there was a substantial increase $(+12 \%$ to $+33 \%)$. This increase was the largest in the Asian/Indian and white/coloured populations but also occurred in the black group. After 1999 the annual percentage 


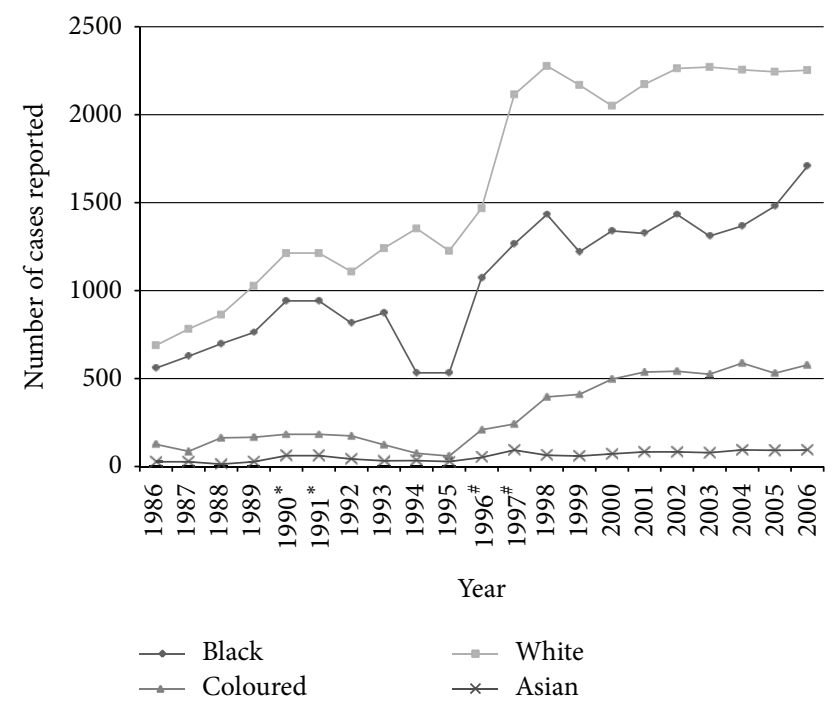

FIgURE 1: Number of prostate cancer cases reported to the South African pathology based National Cancer Registry (NCR) from 1986 to 2006 by the population groups; white, black, coloured, and Asian/Indian. ${ }^{\#} 1996$ and 1997 coloured and whites were pooled together in the published report but NCR provided the number of cases per year. ${ }^{*}$ Years 1990-1991 were combined and reflect the average number of reported cases over the two years.

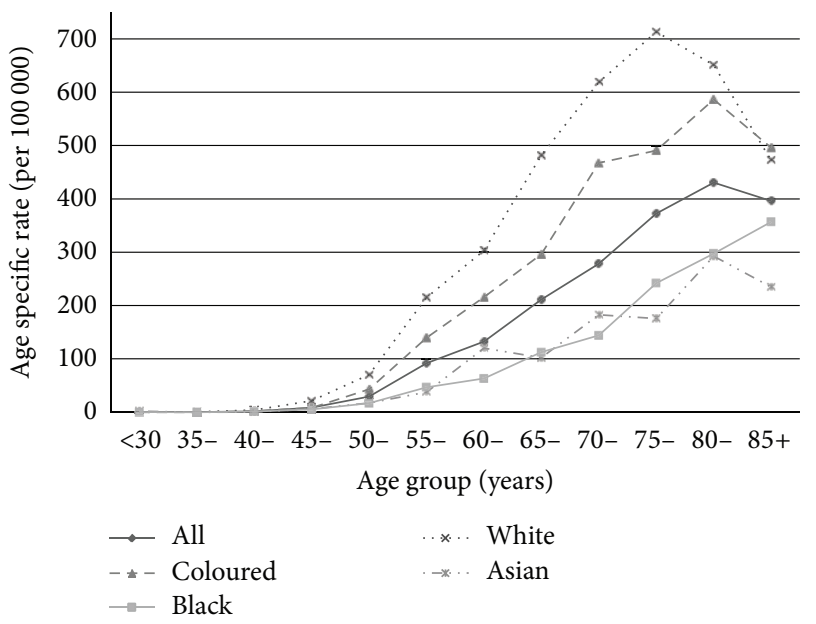

FIGURE 2: South African pathology based National Cancer Registry age specific incidence rate (ASIR) per 100000 for prostate cancer, 2006 , by population group.

change in $\mathrm{CaP}$ numbers decreased to low levels $(+6.6 \%$ to minus $7.5 \%)$. Nearly all (96\%) of the CaPs reported to the NCR from 1999 to 2006 were adenocarcinoma, followed by unspecified carcinomas (3\%).

$\mathrm{CaP}$ was ranked as the number one cancer in SA men since 1996 (excluding basal cell carcinoma). Prior to this $\mathrm{CaP}$ was either second to oesophageal cancer in the black population (1990-1995) or lung cancer in the coloured population (1988 and 1989).

$\mathrm{CaP}$ occurs in men over the age of 45 years and rates steadily increase with age (Figure 2 ). The mean age of men with CaP reported to the NCR in 2006 was 68 years (standard deviation (SD) 9.6); for black men it was 68 years (SD 10.5), for white men it was 67 years (SD 9.0), for coloured men it was 67 years (SD 9.2), and for Asian/Indian men it was 66 years (SD 10.1). From 1986 to $20063.6 \%$ of men with CaP were younger than 50 years of age and 37.6\% were younger than 65 .

The ASR for CaP in SA was 17 per 100000 in 1986, increasing steadily and by 2006 was 27 per 100000 (Table 2). The black population had the lowest ASR of 12 per 100000 compared to 52 per 100000 in white men (Table 2 and Figure 3).

3.2. Mortality. CaP accounted for 1670 deaths in SA in 1999 , 1954 deaths in 2004, and 2331 deaths in 2009 indicating a steady increase (Table 3).

In SA men from 1997 to 2005, CaP was the third leading cause of death through a malignancy (10\%). In 2004 the most frequent cause of death through a malignancy in SA men was lung cancer (17.7\%) followed by oesophageal cancer (12.6\%). In $2006 \mathrm{CaP}$ (12\% of deaths by a malignancy) overtook oesophageal cancer $(10.7 \%)$ to become the second most common cause of death through a malignancy. In 2009 lung cancer was still the most common cause of death by a malignancy in men (19\%), followed by CaP (13\%) and then oesophageal cancer (11\%).

The mean age of men who died from $\mathrm{CaP}$ in 2009 was 74 years (SD 10.6); for black men it was 73 years (SD 10.8), for white men it was 72 years (SD 10.4), for coloured men it was 76 years (SD 10.1), and for Asian/Indian men it was 76 years (SD 9.1). Thirteen percent of malignancy deaths in men were due to $\mathrm{CaP}$, with $78 \%$ being older than 65 years.

In SA the age standardised mortality rate in 2009 for CaP was 16.7 per 100000 and in 1997 it was 12.3 (Table 3). By population group the age standardised mortality rate was 11.4 for black men, 6.8 for white men, 51.9 for coloured men, and 6.3 for Asian/Indian men (Table 4).

3.3. Incidence and Mortality. The proportion of the reported male cancers attributed to $\mathrm{CaP}$ increased from $7 \%$ in 1986 to $17 \%$ in 2006 (Table 2). Almost half of the reported CaP cases were from the white population (Table 1) who represent $9 \%$ of the SA population [13]. Of the 2331 reported deaths from $\mathrm{CaP}$ in 2009, 971 (42\%) were black, 529 (23\%) were from unknown population group, 546 (22\%) were coloured, 251 (11\%) were white, and 34 (2\%) were Asian/Indian. White men represent a higher proportion of cases in the NCR (49\%) but a smaller proportion of deaths from CaP (14\% versus $49 \%$, resp.), compared to black men who represent $37 \%$ of $\mathrm{CaP}$ yet $54 \%$ of the deaths from CaP (Table 4 ). The age standardised rates for incidence (1986-2006) and mortality (1997-2009) have been increasing through the years (Figure 4).

\section{Discussion}

The first published NCR report was in 1986 with a total of 35569 cancers reported in a total population of just under 29.3 million. In 2006, 55241 new cancer cases were reported to the NCR in a total population under 47.5 million people. 


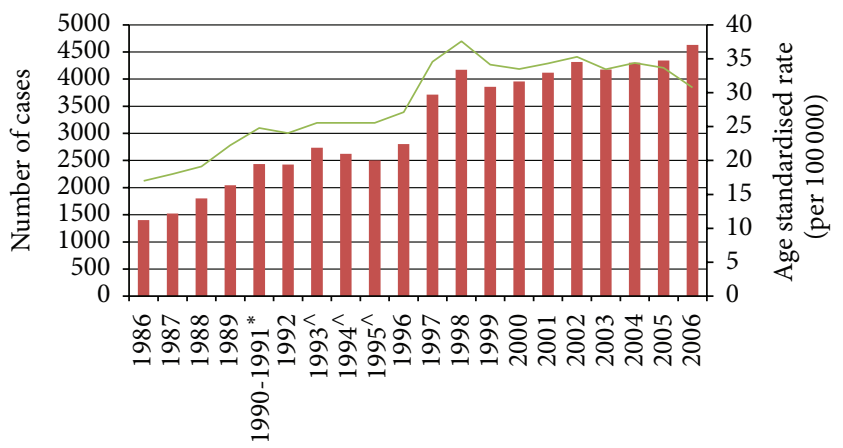

(a) All population group

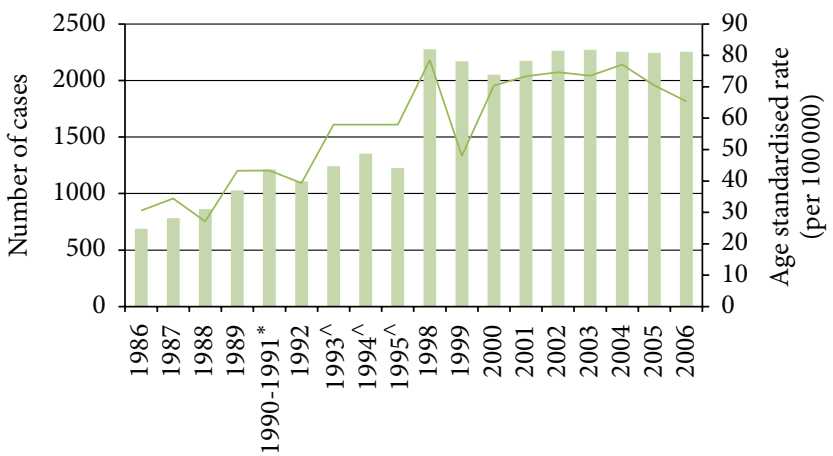

(c) White ${ }^{\#}$

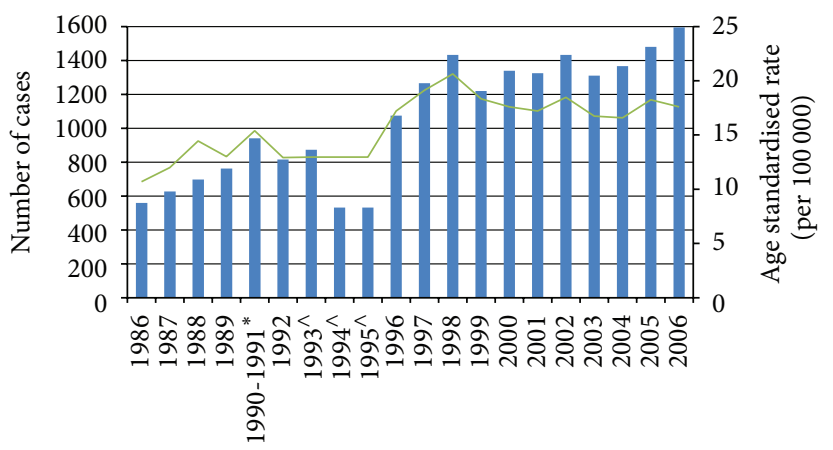

(b) Black

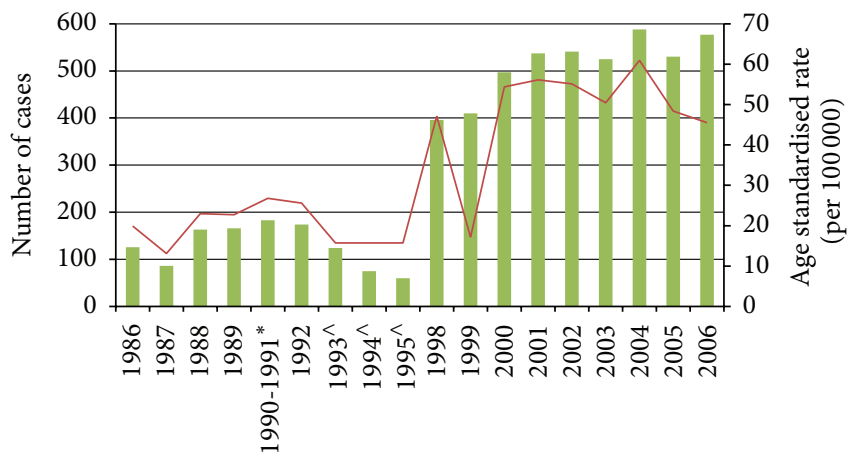

(d) Coloured $^{\#}$

Figure 3: South African pathology based National Cancer Registry reported incidence of prostate cancer, 1988-2006. Columns: number of cases. Line: age standardised incidence rate (ASR). (a) All population groups; (b) black; (c) white; (d) coloured. ^1993-1995 data was combined and the ASR is for the 3-year period. ${ }^{*} 1996$ and 1997 coloured and whites were pooled together and cannot be reported separately. ${ }^{*}$ Years 1990-1991 were combined and reflect the average number of reported cases over the two years. Asian/Indian population had less than 100 cases so not included here.

TABLE 2: South African pathology based National Cancer Registry summary statistics for prostate cancer years 1986-2005 by population group.

\begin{tabular}{|c|c|c|c|c|c|c|c|c|c|c|c|c|c|c|c|}
\hline & \multicolumn{5}{|c|}{ Life time risk (0-74) (LR) } & \multicolumn{5}{|c|}{ Age standardised rates (ASR) } & \multicolumn{5}{|c|}{ Proportion (\%) } \\
\hline & All & Black & White & Coloured & Asian & All & Black & White & Coloured & Asian & All & Black & White & Coloured & Asian \\
\hline 1986 & NR & NR & NR & NR & NR & 16.8 & 10.7 & 30.6 & 19.9 & 15.9 & 7.37 & 8.15 & 6.56 & 9.43 & 8.82 \\
\hline 1987 & NR & NR & $\mathrm{NR}$ & NR & NR & 18.2 & 12.0 & 34.4 & 13.1 & 17.3 & 9.18 & 10.07 & 8.47 & 8.99 & 12.98 \\
\hline 1988 & 1 in 44 & 1 in 52 & 1 in 32 & 1 in 38 & 1 in 173 & 19.1 & 14.4 & 27.1 & 23.0 & 6.5 & 7.68 & 8.00 & 7.11 & 9.12 & 4.56 \\
\hline 1989 & 1 in 39 & 1 in 64 & 1 in 21 & 1 in 40 & 1 in 52 & 22.3 & 13.0 & 43.3 & 22.8 & 14.3 & 8.14 & 8.21 & 8.26 & 9.51 & 7.34 \\
\hline 1990-1991* & 1 in 32 & 1 in 49 & 1 in 19 & 1 in 29 & 1 in 60 & 24.8 & 15.4 & 43.3 & 26.8 & 13.5 & 8.68 & 8.80 & 8.46 & 11.23 & 4.21 \\
\hline 1992 & 1 in 33 & 1 in 58 & 1 in 20 & 1 in 35 & 1 in 67 & 24.1 & 12.9 & 39.3 & 25.6 & 11.7 & 9.36 & 9.00 & 8.97 & 12.11 & 10.02 \\
\hline $1993-1995^{*}$ & 1 in 31 & 1 in 61 & 1 in 14 & 1 in 50 & 1 in 47 & 25.5 & 13.0 & 58.0 & 15.8 & 17.6 & 10.91 & 10.43 & 10.86 & 12.23 & 8.23 \\
\hline $1996^{\dagger}$ & 1 in 31 & 1 in 50 & \multicolumn{2}{|c|}{1 in 18} & 1 in 39 & 27.1 & 17.2 & \multicolumn{2}{|r|}{45.7} & 18.9 & 11.10 & 11.48 & \multicolumn{2}{|c|}{10.97} & 8.86 \\
\hline $1997^{\dagger}$ & 1 in 24 & 1 in 47 & \multicolumn{2}{|c|}{1 in 23} & 1 in 29 & 34.6 & 19.1 & \multicolumn{2}{|c|}{37.9} & 32.4 & 12.59 & 12.49 & \multicolumn{2}{|c|}{7.91} & 12.99 \\
\hline 1998 & 1 in 22 & 1 in 42 & 1 in 10 & 1 in 17 & 1 in 46 & 37.6 & 20.6 & 78.5 & 47.1 & 20.4 & 14.14 & 13.41 & 14.59 & 15.88 & 11.09 \\
\hline 1999 & 1 in 24 & 1 in 39 & 1 in 19 & 1 in 50 & 1 in 39 & 34.1 & 18.3 & 48.0 & 17.2 & 18.3 & 13.12 & 10.85 & 14.66 & 12.42 & 10.85 \\
\hline 2000 & 1 in 24 & 1 in 47 & 1 in 11 & 1 in 15 & 1 in 38 & 33.5 & 17.6 & 70.4 & 54.4 & 23.0 & 14.01 & 14.45 & 13.62 & 14.96 & 12.01 \\
\hline 2001 & 1 in 23 & 1 in 48 & 1 in 11 & 1 in 14 & 1 in 34 & 34.3 & 17.2 & 73.4 & 56.1 & 22.9 & 13.80 & 13.97 & 13.41 & 15.17 & 13.27 \\
\hline 2002 & 1 in 23 & 1 in 46 & 1 in 11 & 1 in 15 & 1 in 44 & 35.3 & 18.5 & 74.7 & 55.1 & 22.2 & 15.35 & 15.70 & 14.85 & 16.98 & 14.30 \\
\hline 2003 & 1 in 24 & 1 in 49 & 1 in 11 & 1 in 17 & 1 in 42 & 33.4 & 16.7 & 73.5 & 50.4 & 18.2 & 14.87 & 15.44 & 14.48 & 15.83 & 12.82 \\
\hline 2004 & 1 in 23 & 1 in 48 & 1 in 10 & 1 in 13 & 1 in 34 & 34.4 & 16.6 & 77.1 & 60.9 & 23.2 & 15.63 & 16.04 & 15.10 & 17.03 & 15.28 \\
\hline 2005 & 1 in 24 & 1 in 48 & 1 in 14 & 1 in 16 & 1 in 35 & 33.7 & 18.2 & 70.5 & 48.4 & 23.0 & 16.84 & 17.12 & 16.92 & 16.70 & 15.46 \\
\hline 2006 & 1 in 27 & 1 in 52 & 1 in 12 & 1 in 18 & 1 in 43 & 30.8 & 17.6 & 65.4 & 45.5 & 18.8 & 17.28 & 17.87 & 16.94 & 17.61 & 13.81 \\
\hline
\end{tabular}

${ }^{*}$ Summary statistics for the years 1990-1991 (2 years) together, 1993-1995 (3 years) together, and ${ }^{\dagger}$ white and coloured population groups were pooled. NR: not reported. Asian is the Asian/Indian population group. 
TABLE 3: Summary information for statistics South Africa mortality, from 1997 to 2009, ICD-10 code C61, prostate cancer.

\begin{tabular}{lcccc}
\hline Year & $\begin{array}{c}\text { Number of reported deaths } \\
\text { from Prostate Cancer }\end{array}$ & $\begin{array}{c}\text { Proportion (\%) of all reported } \\
\text { male deaths by malignancy }\end{array}$ & Crude rate for men & $\begin{array}{c}\text { Age standardised } \\
\text { mortality rate for men }\end{array}$ \\
\hline 1997 & 1498 & 9.38 & 7.23 & 12.29 \\
1998 & 1553 & 9.26 & 7.37 & 12.59 \\
1999 & 1670 & 9.71 & 8.06 & 13.27 \\
2000 & 1752 & 10.18 & 8.07 & 13.71 \\
2001 & 1779 & 10.38 & 8.15 & 13.71 \\
2002 & 1819 & 10.21 & 8.48 & 13.95 \\
2003 & 1914 & 10.56 & 8.58 & 14.53 \\
2004 & 1954 & 10.57 & 8.72 & 14.65 \\
2005 & 2005 & 11.09 & 9.26 & 14.90 \\
2006 & 2160 & 12.00 & 9.40 & 14.94 \\
2007 & 2216 & 11.95 & 9.88 & 14.71 \\
2008 & 2317 & 12.67 & 9.77 & 15.60 \\
2009 & 2331 & 13.30 & & 16.67 \\
\hline
\end{tabular}

TABLE 4: Prostate cancer in South Africa, comparison of 2009 mortality data by population group (when population group was known) to 2006 cancer incidence of reported cases to the pathology based National Cancer Registry (latest report available).

\begin{tabular}{|c|c|c|c|c|c|c|}
\hline & \multicolumn{3}{|c|}{2009 mortality } & \multicolumn{3}{|c|}{2006 cancer incidence } \\
\hline & Total number of cases & $\%$ & $\begin{array}{c}\text { Age standardized mortality } \\
\text { rate }\end{array}$ & $\begin{array}{c}\text { Total number of cases } \\
\text { (adjusted) }\end{array}$ & $\%$ & $\begin{array}{l}\text { Age standardized } \\
\text { incidence rate }\end{array}$ \\
\hline All & 2331 & - & 16.7 & 4631 & - & 30.8 \\
\hline Black & 970 & 54 & 11.4 & 1707 & 37 & 17.6 \\
\hline White & 251 & 14 & 6.8 & 2253 & 49 & 65.4 \\
\hline Coloured & 546 & 30 & 51.9 & 577 & 12 & 45.5 \\
\hline Asian & 34 & 2 & 6.2 & 93 & 2 & 18.8 \\
\hline
\end{tabular}

Since 1986 the cancer burden increased by $64 \%$ while the population increased by $62 \%$, a minor increase in cancer.

As SA has a pathology based registry, CaP cases that were diagnosed without a biopsy but with a digital rectal examination (DRE) and PSA [7] would not be captured [23]. Thus, the true rate of $\mathrm{CaP}$ in SA men is higher than the data indicates.

A rural/regional population based registry (PROMEC) based in the Eastern Cape Province of SA reported an ASR of 4.4 per 100000 for $\mathrm{CaP}$ in 1998-2002 [24], versus the 17 per 100000 from the NCR data for the SA black population. This could be a reflection of poor access to services in the Eastern Cape but it may also reflect different environmental exposures in this rural setting and may be a consequence of low prevalence rather than failure to diagnose and register cases [7]. However, the Eastern Cape has a large migratory population and men in particular may relocate to larger cities seeking work. These men may ultimately be diagnosed and treated in urban areas and would not reflect in the PROMEC registry [25]. Compared to other sub-Saharan African countries, our data does report a lower rate of $\mathrm{CaP}$ for the black population (Figure 5). For example in Zimbabwe, a neighbouring country with a population based registry, the
ASR is 38.1 per 100000 (1998-2002) [5]. It is highly likely that there is an underestimation of incidence from NCR data.

As cancer and in particular $\mathrm{CaP}$ is a disease of age we must consider the age distribution of the population with a number of competing causes of mortality in the various SA population groups. It also needs to be noted that there is a massive age structure difference between the SA population groups. SA has an intermediate aged population with an average age of 25 years: 21 years for the black population, 26 years for the coloured population, 32 years for the Asian/Indian population, and 38 years for the white population [13]. In 2004 the life expectancy at birth was 51.4 years for the total SA population, for black men it was 47.8 years whereas for white men it was 61.7 years [26]. By 2011 the life expectancy at birth for SA men increased to 54.9 years [27]. Despite this, there is little variation in age at diagnosis between the different population groups, all being in the region of 68 years old at diagnosis and 74 years old at death. However, the cancer stage at presentation is unknown, and therefore we cannot determine if any possible lead time bias occurred in any particular population group. From 1986 to 2006, 3.6\% were younger than 50 years of age and $37.6 \%$ were younger than 65 (Figure 2); this is far more than the reported percentage of 


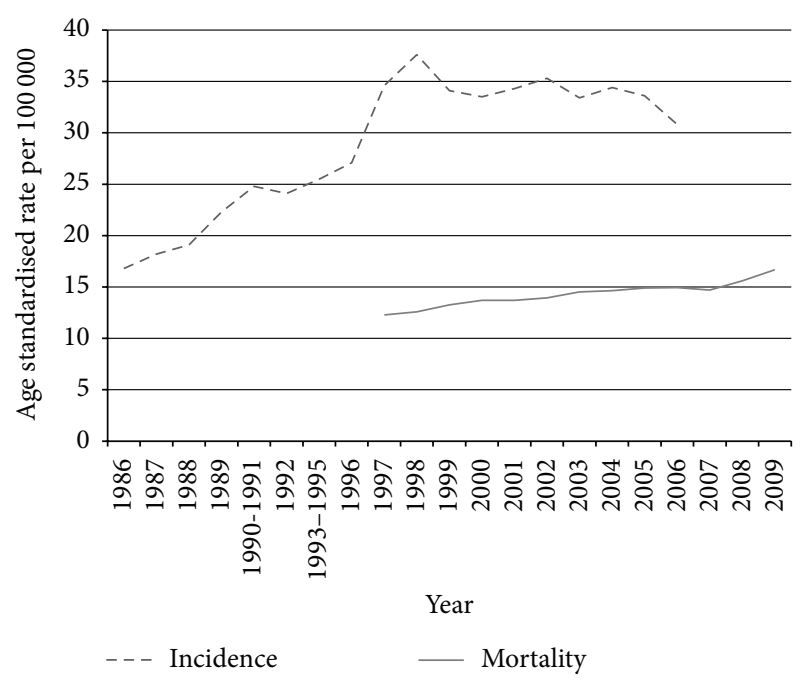

FIgURE 4: Prostate cancer in South Africa, age standardised incidence rate (1986-2006) from the pathology based National Cancer Registry and age standardised mortality (1997-2009) rate from Statistics SA mortality data, per 100000.

$<0.1 \%$ of all patients and about $85 \%$ being diagnosed after the age of 65 [28]. In the UK $12 \%$ of malignancy deaths in men were due to CaP, with $93 \%$ older than 65 years [29]. This may however, again, reflect the age structure of the SA population.

Some points to consider about NCR reports are only pathology based cases reported; the 1990-1991 NCR report has summarised data reported for the two years as one. The 1993 to 1995 NCR report is similar, with summarised data reported for all 3 years as one, but the numbers of observed cases are given per year. The 1996-1997 NCR report has the coloured and white population groups pooled together; however the NCR was able to provide the reported numbers reported for each group separately. Since 1996 the observed numbers of cases were adjusted to take into consideration the unknowns (cases reported with no age or undetermined population). From 1998 there were positive changes in the NCR data coding, capturing protocols, and the detection of duplicates, improving the quality of data.

The incidence of $\mathrm{CaP}$ is influenced largely by testing and, where testing is common practice with subsequent biopsy, $\mathrm{CaP}$ rates are likely to increase. As a result, countries that implemented PSA testing, many in the 1990s, saw an increase of $\mathrm{CaP}$ after the introduction, followed by a decrease and then stabilisation of CaP numbers a few years later [10]. Globally, several trials to determine effectiveness of PSA testing have been done with no conclusive resolution of effectiveness and the cost benefit in asymptomatic men [30,31]. There is concern around PSA testing in that it may result in over diagnosis [10]. PSA testing does have value in diagnosing symptomatic early stage $\mathrm{CaP}$ and for monitoring treatment response [28]. However, a test capable of determining the risk of having $\mathrm{CaP}$ with rapid progression is lacking and there is a need to identify life-threatening $\mathrm{CaP}$ and potential progression of disease.

In $\mathrm{SA}$, the period of introduction and the frequency of testing with PSA are unclear. But in the mid-90s PSA testing did become more popular and was more frequently used in diagnosis of $\mathrm{CaP}$ (personal communication). The NCR data does indicate that there was a sudden increase in the number of $\mathrm{CaP}$ cases across all population groups (Table 1 and Figure 1) and this increase in the mid-90s was not seen with other cancers in the NCR reports. It is highly probable that the introduction of PSA testing was responsible for the increase of $\mathrm{CaP}$ cases being diagnosed from 1996 to 1999 (Figure 1).

PSA testing in asymptomatic men can be considered not to be readily available in the SA public health care sector and most men will present with symptoms before being tested [32]. However, it may be more readily available in the SA private health care sector. Having medical aid cover allows for access to private healthcare facilities. In 2011, 69.7\% of the white population belonged to a medical scheme, with $41.1 \%$ of the Asian/Indian population, $20.3 \%$ of the coloured population, and $8.9 \%$ of the black population [33]. This may explain the incidence versus mortality rate seen in white men (Table 4); as they are likely to belong to a medical aid scheme they have access to a private health care facility that will, possibly, more readily provide PSA testing. These men may get diagnosed earlier and receive life-saving treatment or potentially unnecessary treatment. In the UK, where the health care system is free and has less variation in quality of care by socioeconomic status, a study comparing black men with white men found, apart from early age of onset in black men, that there was no evidence of differences in disease characteristics at the time of $\mathrm{CaP}$ diagnosis or of underinvestigation or under treatment in UK black men compared to UK white [9]. It may be that in SA differential detection by population group is due to differences in socioeconomic characteristics such as access to and use of health care facilities [14, 28]; this is one of many possible factors.

Heyns et al. in the Western Cape Province of SA looked at PSA use in their public health care centre. They found a significant problem in getting men with an elevated serum PSA ( $>4 \mathrm{ng} / \mathrm{mL}$ ) to undergo a prostate biopsy, with uptake ranging from $19 \%$ to $47 \%$ in the different population groups, black and coloured, respectively [23]. Although an earlier, unpublished study by the same centre experienced uptake (when biopsy was indicated) between $53 \%$ and $87 \%$, for black and white / mixed ancestry, respectively [23]. This is one center's experience and the ages of the nonbiopsied were not provided (older men may not have wanted to be biopsied due to quality of life concerns). However, if the situation is similar throughout SA, it could also contribute to underestimation of $\mathrm{CaP}$ when a pathology based registry is in operation. Further studies are required to determine to what extent uptake for a biopsy after an elevated PSA is detected, why it is occurring, and how uptake for a biopsy could be improved.

The 2011 census indicated that $79.2 \%$ of the SA population were black, $8.9 \%$ white, $8.9 \%$ coloured, and $2.5 \%$ Asian/Indian. The incidence and mortality rates do not appear to reflect the demographics of the country (Table 4). Additional research is required to identify these issues and develop interventions that will minimize these effects.

Compared to incidence, mortality is less often affected by diagnostic and screening practices but reflect differences 


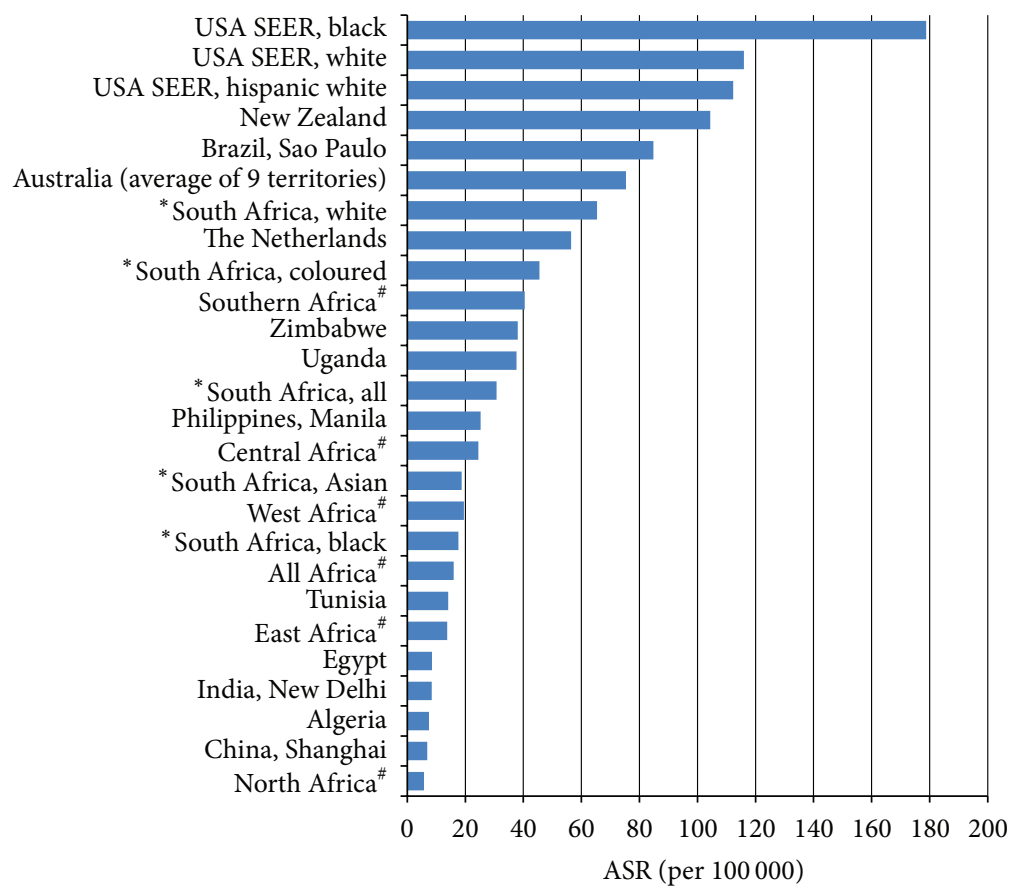

FIGURE 5: Comparison of age standardised rates (ASR) per 100000 for prostate cancer from Curado et al. 1998-2002 [5], Parkin et al. 2002 (\#) [37], and South African pathology based National Cancer Registry 2006 (*).

in $\mathrm{CaP}$ treatment worldwide, as well as underlying risk [10]. GLOBOCAN (2008) reported an overall mortality rate for Southern Africa as 19.3 (per 100 000), 9.9 for N. America and 12 for Europe [34]. In SA the age standardised mortality rate in 2008 for $\mathrm{CaP}$ was 15.7 per 100 000; in 1997 it was 12.3 (Table 3 ). By population group the age standardised mortality rate was 11.4 for black men, 6.8 for white men, 51.9 for coloured men, and 6.3 for Asian/Indian men (Table 4). Coloured SA men have the highest mortality rate.

Awareness campaigns on men's health, such as Movember [35] and other similar campaigns should be further developed, testing drives and improved education around men's health; CaP and improved follow-up of potential patients that have increased PSA levels are all required. Other risk factors such as healthcare access, lifestyle, medical care beliefs/practices, environmental exposures, or biological (including genetic) mechanisms may also be influencing the disparities between the populations and need to be further investigated. In addition the influence of HIV and its management on risk of $\mathrm{CaP}$ is also still unknown and needs to be explored [36].

\section{Conclusion}

$\mathrm{CaP}$ is a growing problem in SA and globally; it is the most common cancer in men and the second most common malignancy causing death for men. We acknowledge that SA NCR CaP incidence rates are an underestimate of the total burden of this cancer in the country, due to the fact that the NCR records only microscopically verified cases and that not all geographic areas and sociodemographic groups have equal access to all tiers of health services. In spite of these limitations the NCR data, combined with the national cancer-specific mortality data, do provide insight into the demographics of $\mathrm{CaP}$ in $\mathrm{SA}$ as they give minimum incidence and rates. The results give an indication of the bare minimum numbers of $\mathrm{CaP}$ cases that have been diagnosed and which need to be accommodated in the SA health care system. As well as possible genetic influences, lifestyle and health care access will account for some of the differences between population groups and it is possibly an indication that reporting and diagnostics for $\mathrm{CaP}$ are not adequate in $\mathrm{SA}$. It is also anticipated that there will be an increase of CaP in SA as lifestyles change and the SA population advances in age with the life expectance rising. A better understanding of the burden of $\mathrm{CaP}$ in SA, as well as studies to determine the appropriate care programs required, ensuring adequate and appropriate diagnosis and treatment in all sectors are needed. The data presented here is the only consolidated data available for SA. Despite the limitations of the data it provides information for researchers, clinicians, policy makers, NGOs, and other stakeholders working with men's health and CaP.

There is a need for improvements in awareness, diagnosis, and treatment of CaP. Future expansion of the SA NCR to include hospital and population based components will assist in tracking changes. A better understanding of the aetiology and underlying biological mechanisms to modifiable risk 
factors of $\mathrm{CaP}$ across all populations can potentially improve the care of all $\mathrm{CaP}$ patients everywhere and could have implications for selective testing, prevention, and treatment options, ensuring valuable resources are appropriately utilized.

\section{Conflict of Interests}

The authors declare that there is no conflict of interests regarding the publication of this paper.

\section{Acknowledgments}

The authors are grateful to Statistics SA for providing data on mortality. They acknowledge the NCR for their tireless work. The NHLS/MRC Cancer Epidemiology Research Group at the National Health Laboratory Services (NHLS) is currently funded by the South African Medical Research Council (MRC) and the South African NHLS. Dr Babb has Project A funding from CANSA (Cancer Association of South Africa) for research into genetic susceptibility to $\mathrm{CaP}$ in black SA men.

\section{References}

[1] B. L. Chang, E. Spangler, S. Gallagher et al., "Validation of genome-wide prostate cancer associations in men of african descent," Cancer Epidemiology, Biomarkers \& Prevention, vol. 20, pp. 23-32, 2011.

[2] T. R. Rebbeck, S. S. Devesa, B. L. Chang et al., "Global patterns of prostate cancer incidence, aggressiveness, and mortality in men of african descent," Prostate Cancer, vol. 2013, Article ID 560857, 12 pages, 2013.

[3] M. P. Zeegers, L. A. L. M. Kiemeney, A. M. Nieder, and H. Ostrer, "How strong is the association between CAG and GGN repeat length polymorphisms in the androgen receptor gene and prostate cancer risk?" Cancer Epidemiology Biomarkers and Prevention, vol. 13, no. 11, pp. 1765-1771, 2004.

[4] E. M. Lange, A. V. Sarma, A. Ray et al., "The androgen receptor CAG and GGN repeat polymorphisms and prostate cancer susceptibility in African-American men: results from the Flint Men's Health Study," Journal of Human Genetics, vol. 53, no. 3, pp. 220-226, 2008.

[5] M. P. Curado, B. Edwards, H. R. Shin et al., Cancer Incidence in Five Continents, vol. 9, IARC Scientific, 2007.

[6] D. M. Parkin, J. Ferlay, M. Hamdi-Chérif et al., Cancer in Africa-Epidemiology and Prevention, No. 153, IARC Scientific, 2003.

[7] C. F. Heyns, M. Fisher, A. Lecuona, and A. van der Merwe, "Prostate cancer among different racial groups in the western cape: presenting features and management," South African Medical Journal, vol. 101, no. 4, pp. 267-270, 2011.

[8] L. W. Chu, J. Ritchey, S. S. Devesa, S. M. Quraishi, H. Zhang, and A. W. Hsing, "Prostate cancer incidence rates in Africa," Prostate Cancer, vol. 2011, Article ID 947870, 6 pages, 2011.

[9] S. Evans, C. Metcalfe, B. Patel et al., "Clinical presentation and initial management of Black men and White men with prostate cancer in the United Kingdom: the PROCESS cohort study," British Journal of Cancer, vol. 102, no. 2, pp. 249-254, 2010.
[10] M. M. Center, A. Jemal, J. Lortet-Tieulent et al., "International variation in prostate cancer incidence and mortality rates," European Urology, vol. 61, no. 6, pp. 1079-1092, 2012.

[11] N. Mqoqi, P. Kellett, F. Sitas, and M. Jula, Incidence of Histologically Diagnosed Cancer in South Africa, 1998-1999, National Cancer Registry, 2004.

[12] "National Cancer Registry Reports, National Health Laboratory Service," 2013, http://www.nioh.ac.za/?page=national_cancer_ registry\&id $=41$.

[13] Census 2011. Statistics South Africa Stats release P0301. 4, 2011.

[14] V. McCormack, M. Joffe, E. van den Berg et al., "Breast cancer receptor status and stage at diagnosis in over 1, 200 consecutive public hospital patients in Soweto, South Africa: a case series," Breast Cancer Research, vol. 15, article R84, 2013.

[15] N. M. Dube, B. V. Girdler-Brown, K. S. Tint, and P. Kellett, "Repeatability of manual coding of cancer reports in the South African National Cancer Registry," Southern African Journal of Epidemiology and Infection, vol. 28, pp. 157-165, 2013.

[16] D. Kielkowski, E. Singh, K. Wilson, C. Babb, M. Urban, and P. Kellett, "Reply: the South African paediatric tumour registry25 years of activity," South African Medical Journal, vol. 102, article 642, 2012.

[17] M. H. Abram, W. F. P. van Heerden, P. Rheeder, B. V. GirdlerBrown, and A. W. van Zyl, "Epidemiology of oral squamous cell carcinoma," SADJ: Journal of the South African Dental Association, vol. 67, pp. 550-553, 2012.

[18] M. Norval, P. Kellett, and C. Y. Wright, "The incidence and body site of skin cancers in the population groups of South Africa," Photodermatology, Photoimmunology \& Photomedicine, 2014.

[19] R. Dorrington, L. Johnson, D. Bradshaw, and T. Daniel, The Demographic Impact of HIV/AIDS in South Africa National and Provincial Indicators for 2006, Centre for Actuarial Research; South African Medical Research Council and Actuarial Society of South Africa, Cape Town, South Africa, 2006.

[20] R. Doll, P. Payne, and J. A. H. Waterhouse, Cancer Incidence in Five Continents, vol. 1, IARC Scientific, 1966.

[21] R. Dorrington, D. Bradshaw, and D. Bourne, "Two steps forward, one step back: comment on adult mortality (age 1564) based on death notification data in South Africa for 19972001," South African Medical Journal, vol. 96, no. 10, pp. 10281032, 2006

[22] "2006 Adult mortality (age 15-64) based on death notification data in South Africa: 1997-2004. Stat. South Africa release 0309-05," http://www.statssa.gov.za/publications/Report-03-0905/Report-03-09-052004.pdf.

[23] C. F. Heyns, S. Mathee, A. Isaacs, A. Kharwa, P. M. De Beer, and M. A. Pretorius, "Problems with prostate specific antigen screening for prostate cancer in the primary healthcare setting in South Africa," BJU International, vol. 91, no. 9, pp. 785-788, 2003.

[24] N. I. Somdyala, D. Bradshaw, W. C. Gelderblom, and D. M. Parkin, "Cancer incidence in a rural population of South Africa, 1998-2002," International Journal of Cancer, vol. 127, no. 10, pp. 2420-2429, 2010.

[25] N. I. Somdyala, D. Bradshaw, B. Curtis, and W. C. Gelderblom, "Cancer Incidence in Selected Municipalities of the Eastern Cape Province, 1998-2002," PROMEC Cancer Registry Technical Report, South African Medical Research Council, Cape Town, South Africa, 2007. 
[26] C. Day and A. Gray, Health and Related Indicators, South African Health Review, 2005, edited by: Ijumba P., Barron P.

[27] Mid-year population esimates 2011. Statistics South Africa Stats release P0302, 2011.

[28] C. F. Heyns and A. Van Der Merwe, "Prostate specific antigenbrief update on its clinical use," South African Family Practice, vol. 50, no. 2, pp. 19-24, 2008.

[29] Prostate Cancer Statistics, Cancer Research, London, UK, 2011.

[30] J. Donovan and R. Martin, "Commentary: screening for prostate cancer," International Journal of Epidemiology, vol. 36, no. 1, article 30, 2007.

[31] E. M. Wever, G. Draisma, E. A. M. Heijnsdijk et al., "Prostatespecific antigen screening in the United States vs in the European randomized study of screening for prostate cancerRotterdam," Journal of the National Cancer Institute, vol. 102, no. 5, pp. 352-355, 2010.

[32] C. F. Heyns, M. Fisher, A. Lecuona, and A. van der Merwe, "Should baseline PSA testing be performed in men aged 40 to detect those aged 50 or less who are at risk of aggressive prostate cancer?" South African Medical Journal, vol. 101, no. 9, pp. 642644, 2011.

[33] General Household Survey 2011. Statistics South Africa Stats release P0318, 2011.

[34] J. Ferlay, H. Shin, F. Bray, D. Forman, C. Mathers, and D. Parkin, GLOBOCAN, 2008, Cancer Incidence and Mortality Worldwide, IARC CancerBase No. 10, International Agency for Research on Cancer, Lyon, France, 2010.

[35] S. Wright, "Grow a 'tache, save a life," Nursing standard, vol. 27, no. 9, article 24, 2012.

[36] J. Silberstein, T. Downs, C. Lakin, and C. J. Kane, "HIV and prostate cancer: a systematic review of the literature," Prostate Cancer and Prostatic Diseases, vol. 12, no. 1, pp. 6-12, 2009.

[37] D. M. Parkin, F. Sitas, M. Chirenje, L. Stein, R. Abratt, and H. Wabinga, "Part I: cancer in Indigenous Africans-burden, distribution, and trends," The Lancet Oncology, vol. 9, no. 7, pp. 683-692, 2008. 


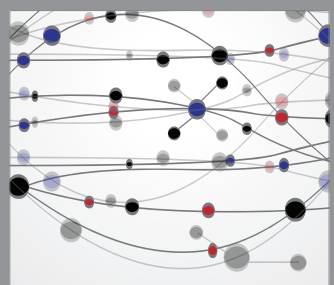

The Scientific World Journal
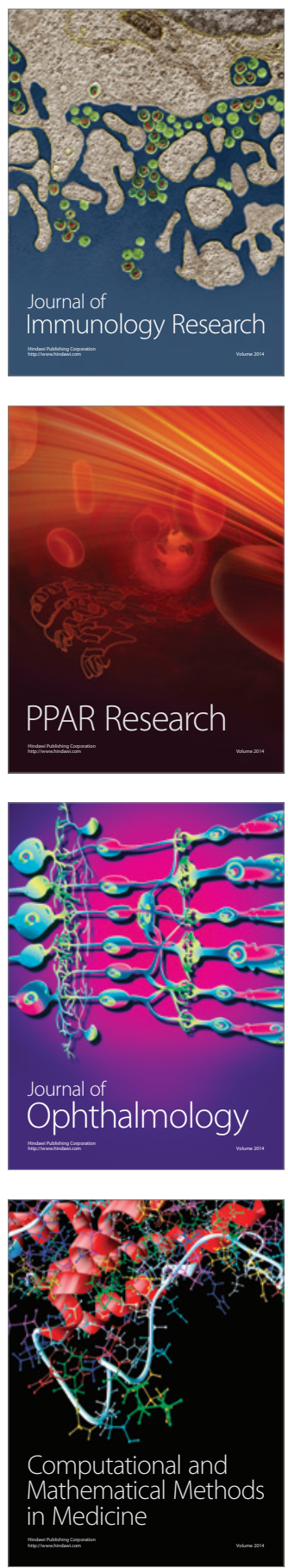

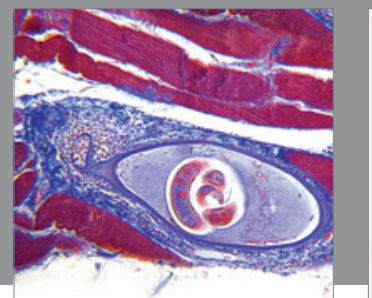

Gastroenterology

Research and Practice
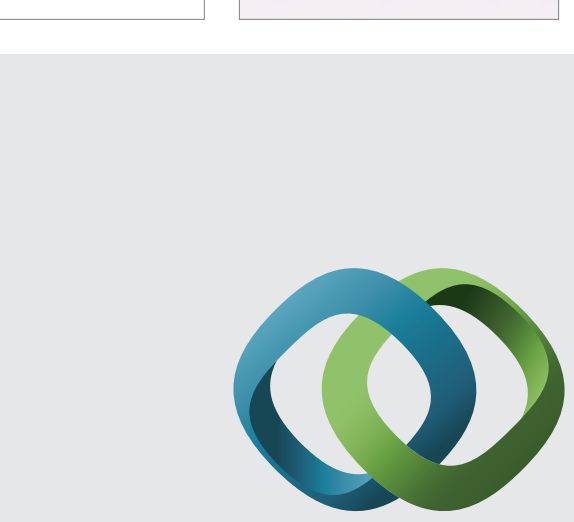

\section{Hindawi}

Submit your manuscripts at

http://www.hindawi.com
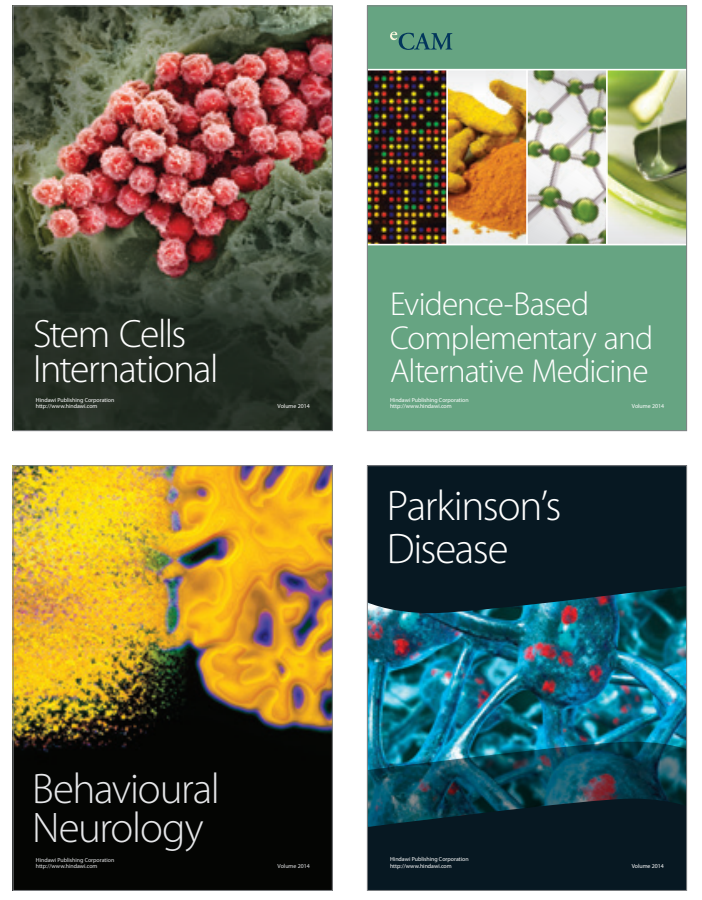
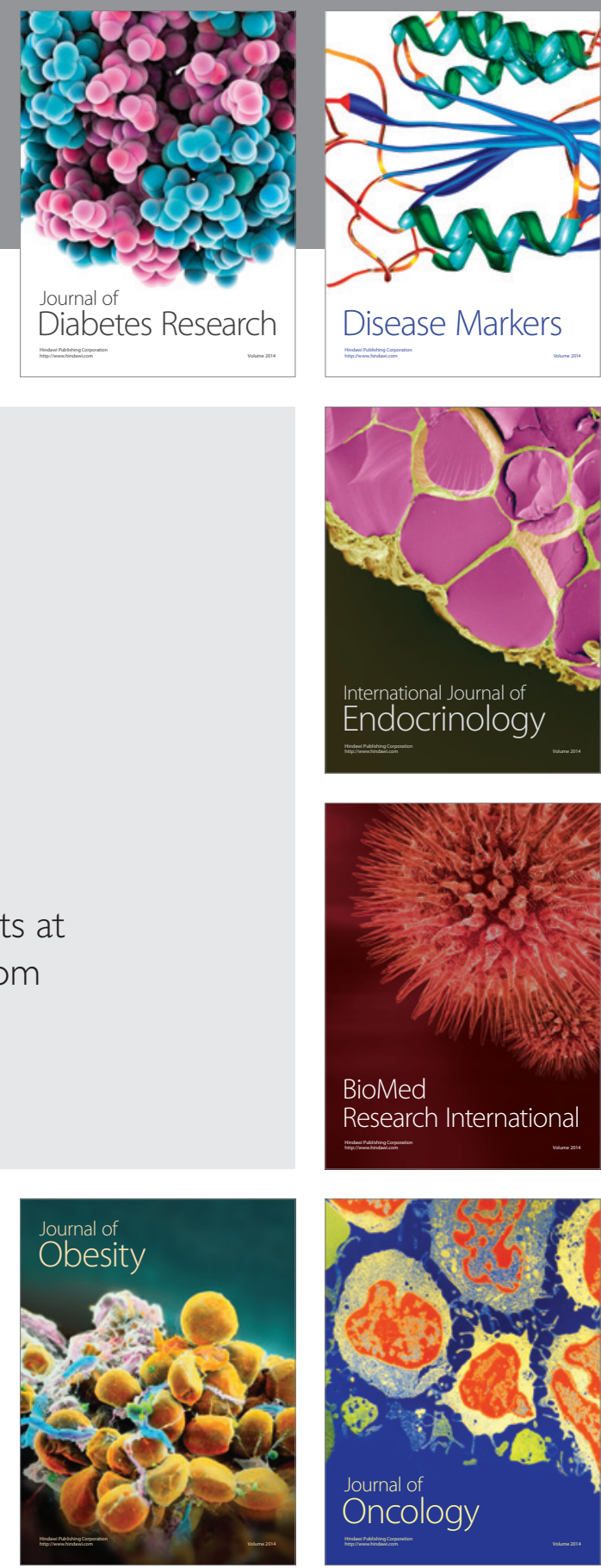

Disease Markers
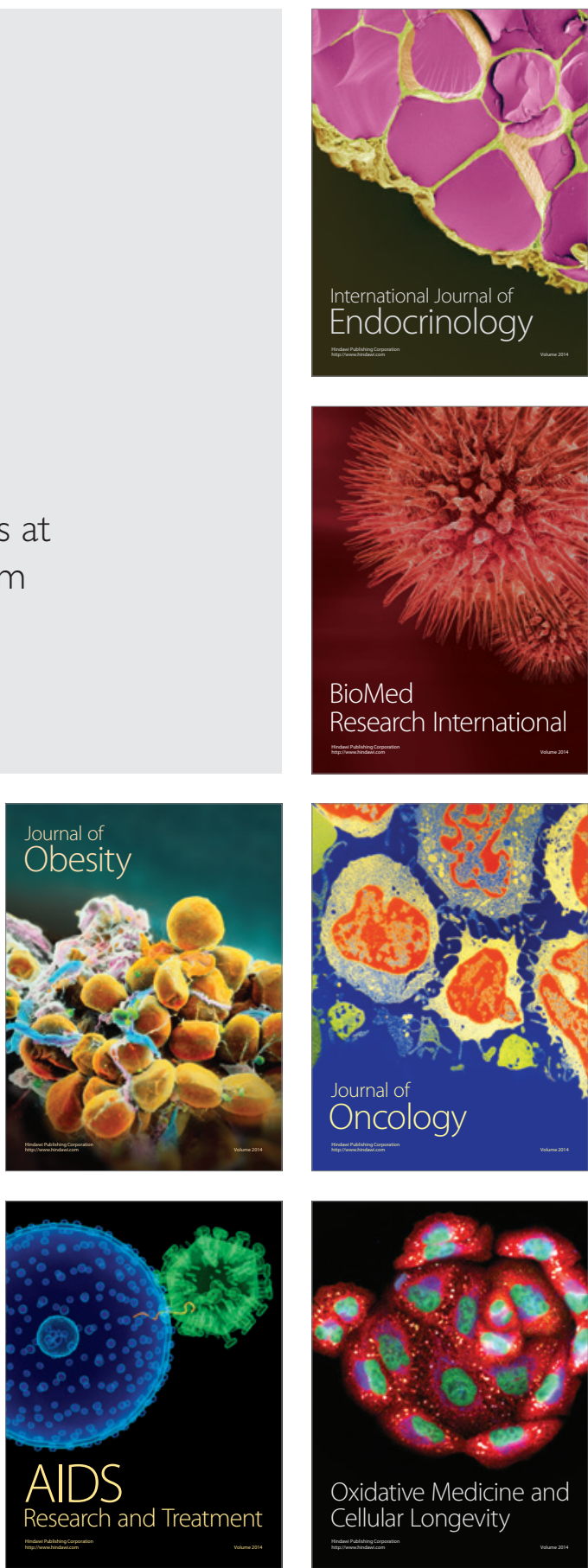